\title{
A Study on the Prosperity Index and Cycle Measurement of China Air Cargo Transport
}

\author{
Jinmei $\mathrm{Ge}^{1^{*}}$ \\ ${ }^{1}$ Planning and Research Institute, China Academy of Civil Aviation Science and Technology, Beijing, China
}

\begin{abstract}
The business cycle of the Air cargo in China is investigated in this paper. Both the composite indicator (CI) and the diffusion indicator (DI) are derived and the benchmark date is determined. The composite index is synthesized by 10 indicators using correlation analysis and the method of NBER. Then the spectral method is adopted in use of the CI to identify the the major cycle of air cargo in China. By the $\mathrm{CI}$, there is a major cycle with the length of 3,6 years. The major cycle of air cargo in China keeps pace with the the global trade fluctuation. The cycle of air cargo of China is compared with the United States, and the railway cargo of China. The author finds out that the major cycle of the air cargo is basically consistent with the USA in the same period. Combined with the prosperity index, it illustrates that the growth of air cargo in China will reach a peak in around 2021-2022, considering the growth of global trade and the leading prosperity index.
\end{abstract}

\section{INTRODUCTION}

The business cycle, that is, the economic cycle, refers to the cyclical changes of economic phenomena or economic variables. The whole idea of economic prosperity analysis method is to select representative indicators and establish a prosperity indicator system to describe the status of the macro-economy or the industry and forecast the future trend. The prosperity index is also called the "barometer" or "alarm" of the macro-economy.

The prosperity index includes diffusion index (DI), composite index (CI) and Stock-Watson Index (SWI). A relatively mature theory of prosperity index has been formed by NBER ${ }^{[1-3]}$. Based on the absolute quantity or increment or growth rate of the index, the prosperity cycle is divided into classical cycle, growth cycle and growth rate cycle. The classical cycle method mainly observes the fluctuation of the absolute quantity of economic time series, as the trend and cycle series (TC). The growth cycle fluctuation is also called the deviation cycle method, which generally observes the fluctuation of the relative quantity of the economic time series, separates the long-term trend $\mathrm{T}$ of the time series from the cycle factor $\mathrm{C}$, and regards the change of the cycle factor $\mathrm{C}$ as the prosperity change. The growth rate cycle observes the growth rate of the economic time series (the rate of change compared with the same month of last year or the same quarter), and analyze the regularity of its fluctuation based on the TC series.

These three methods are adopted by different countries or organizations in the world. The classical cycle method is adopted in the United States, and the growth cycle method is adopted in OECD. For developing countries the growth rate cycle method is most applied [4]. To establish the prosperity indicator system, the benchmark indicator should be determined first. The growth rate of the industrial added value is generally chosen for the macro economy prosperity. For an industry, the growth rate of the profit or the product sales income is generally chosen as the benchmark indicator. Based on the chronological order, the group of economic cycle indicators are often divided into leading, coinciding and lagging indicators. The coinciding indicator represents the situation of the economic cycle. The leading indicator goes before the change of the economic cycle, and the lagging indicator helps to further confirm the turning point of the economic cycle. The main purpose of the prosperity index is to predict the turning point of the fluctuation of the economic cycle. If the leading index rebounds, it indicates that the synchronous index will also recover afterwards.

The industry prosperity released by official statistics in China are the Purchasing manager index (PMI) and China Logistics Industry Prosperity Index (LPI), both of which are DI. The LPI is weighted by total business volume, new orders, employees, inventory turnover times and equipment utilization. As an authoritative information organization, the China National Information Center publishes quarterly frequency of industrial prosperity index, which selects six indicators including industry sales income, total profits, year-onyear growth rate of industry employees, industry export composite index, total tax, and year-on-year growth rate of fixed asset investment.

There are not many researches on the prosperity of the transportation industry, especially the air transport industry. Chen Yu (2009) ${ }^{[5]}$, Guan Jing (2012) ${ }^{[6]}$ calculated the DI and CI of civil aviation based on month

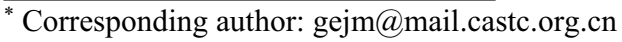


or quarterly data. Zhao ChenShihui (2016) ${ }^{[7]}$ established the railway freight market prospect index based on monthly data from 2005 to 2015 for empirical analysis. Lu Change (2018) ${ }^{[8]}$ analyzed the China's air cargo prosperity index based on supply and demand indicators, but the method was not based on growth rate cycle. GE Jinmei (2020) ${ }^{[9]}$ measured the cycle of China's air cargo demand from 1952 to 2019 by using spectral analysis. The study found that the main cycle of air cargo cycle fluctuation is 5-6 years, and there is a relatively weak cycle fluctuation of about 3 years.

There is very little literature on the air cargo prosperity index area, and the cycle of civil aviation industry. The outbreak of the Covid-19 epidemic has brought a great impact on the global aviation industry, but it is also an opportunity for the development of air cargo transport. The study of the business cycle fluctuation of air cargo transport is helpful to plan the development of the industry and deepen the understanding of the development of the air freight industry.

The structure of the paper is as follows. Firstly, this paper establishes the air cargo prosperity indicator system based on the annual data, then it determines the reference date by calculating the diffusion index (DI). Then it analyze the status of the air cargo transport by calculating the composite index $(\mathrm{CI})$ with the growth rate cycle. Based on the CI, the length of the cycle is measured and a comparative analysis between China and the United States is carried out. Finally, conclusions are given.

\section{THEORETICAL FRAMEWORK OF PROSPERITY METHOD AND WINDOW SPECTRUM METHOD}

\subsection{Theoretical framework of Prosperity analysis}

In order to analyze the prosperity of the air cargo industry, it is necessary to determine the indicator group and calculate the CI and DI to analyze it.

\subsection{1 determine the prosperity indicator group}

This paper use time difference correlation analysis to screen the indicators based on growth rate cycle. The time difference correlation coefficients of several different delay numbers are calculated and compared, and the maximum time difference correlation coefficient is considered to reflect the time difference correlation between the selected index and the benchmark index, with the corresponding delay number indicates lead or lag.

$\mathrm{y}$ is the benchmark index, $\mathrm{x}$ is the indicator to be selected, $r$ is the correlation coefficient of time difference.

$$
\boldsymbol{y}=\left\{y_{1}, y_{2}, \cdots, y_{n}\right\} \boldsymbol{x}=\left\{x_{1}, x_{2}, \cdots, x_{n}\right\}
$$

$$
r_{l^{\prime}}=\max _{-L \leq l \leq L} r_{l}
$$

Where

$$
\begin{gathered}
r_{l}=\frac{\sum_{t=1}^{n_{l}}\left(x_{t-l}-\bar{x}\right)\left(y_{t}-\bar{y}\right)}{\sqrt{\sum_{t=1}^{n_{l}}\left(x_{t-l}-\bar{x}\right)^{2} \sum_{t=1}^{n_{l}}\left(y_{t}-\bar{y}\right)^{2}}} \\
l=0, \pm 1, \pm 2, \cdots, \pm L
\end{gathered}
$$

$l$ indicates leading or lagging period. If it is negative, it means to be ahead of time. If it is positive if means to be a lag. $L_{\text {Is }}$ the maximum number of delays, ${ }^{n}$ is the number of data.

The final index group includes coinciding, leading and lagging indicators.

$$
\mathrm{I}(t)=\left\{x_{i j t}\right\}
$$

Where $\mathrm{j}=1,2,3$ represents leading, coinciding and lagging indicator group, respectively. $\mathrm{i}=1,2, \ldots, \mathrm{k}$, represents the number of indicators in the indicator group.

\section{1 .2 calculation of $D I$}

The diffusion index (DI), which determines the prosperity trend of air cargo mainly depends on the calculation of the direction change of each index in the group. The rule of calculation is that the interval of each sequence from valley to peak is raised, marked with "+", and the peak itself is marked with "+". The range from peak to valley is marked with "-", and the valley itself is marked with "-". The percentage of the number of indicators rising each year in the total number of indicators of prosperity indicators is DI.

$$
D I_{i}=\frac{\sum I\left[X_{t}, X_{t-j}\right]}{N} \times 100
$$

Where

$$
\mathrm{I}\left[X_{t}, X_{t-j}\right]=\left\{\begin{array}{l}
1, X_{t}>X_{t-j} \\
0.5, X_{t}=X_{t-j} \\
0, X_{t}<X_{t-j}
\end{array}\right.
$$

\subsection{3 calculation of $\mathrm{Cl}$ based on growth rate cycle}

The growth rate of each index was synthesized. First of all, data processing. Calculate the symmetrical change rate of the index and standardize it.

$\mathrm{X}_{\mathrm{ij}(\mathrm{t})}$ is the $\mathrm{i}$ index of the $\mathrm{j}$ index group. $\mathrm{C}_{\mathrm{ij}(\mathrm{t})}$ is the symmetrical change rate.

$$
C_{i j}(t)=\left\{\begin{array}{c}
200 \times \frac{X_{i j}(t)-X_{i j}(t-1)}{X_{i j}(t)+X_{i j}(t-1)}, \quad X_{i j}(t)>0 \\
X_{i j}(t)-X_{i j}(t-1), X_{i j}(t) \leq 0 \\
t=2,3, \cdots n
\end{array},\right.
$$


The symmetrical change rate $\mathrm{C}_{\mathrm{ij}(\mathrm{t})}$ of each index is standardized so that its average absolute value is equal to 1 .

$$
S_{i j}(t)=\frac{C_{i j}(t)}{A_{i j}}, t=2,3, \ldots n
$$

Where

$$
A_{i j}=\sum_{t=2}^{n} \frac{\left|C_{i j}(t)\right|}{n-1}
$$

The third step is to find the standardized average change rate of each index group. The amplitude of the average rate of change of the consistent index series is used to adjust the average rate of change of the leading index series and the lagging index series. The purpose is to apply the three indexes as a coordinated system.

$$
V_{j}(t)=\frac{\sum_{i=1}^{k_{j}} R j(t) w_{i j}}{\mathrm{~F}_{i=1}^{k j} w i j} t=2,3, \cdots n
$$

Where,

$$
R_{j}(t)=\frac{\sum_{i=1}^{k_{j}} S_{i j}(t) \cdot w_{i j}}{\sum_{i=1}^{k_{j}} w_{i j}}
$$

$j=1,2,3 ; t=2,3, \ldots n$

$\mathrm{R}_{\mathrm{j}(\mathrm{t})}$ is the average rate of change of index group. $\mathrm{W}_{\mathrm{ij}}$ is the weight of the I index of group $\mathrm{j}$, and $\mathrm{Fj}$ is the index standardization factor.

$$
\begin{gathered}
F_{j}=\left[\sum_{t=2}^{n}\left|R_{j}(t)\right| /(n-1)\right] /\left[\sum_{t=2}^{n}\left|R_{2}(t)\right| /(n-1)\right] \\
j=1,2,3,
\end{gathered}
$$

Then the composite index $\mathrm{I}_{\mathrm{j}(\mathrm{t})}$ can be calculated.

$$
\begin{gathered}
C I_{j}(t)=\left(I^{\prime}{ }_{j}(t) / \overline{I^{\prime}}{ }_{j}\right) \times 100 \\
I_{j}(t)=I_{j}(t-1) \times \frac{200+V_{j}(t)}{200-V_{j}(t)}
\end{gathered}
$$

$j=1,2,3 ; t=2,3, \ldots n$

Where

$$
\begin{gathered}
\overline{I_{j}^{\prime}}=\frac{\sum I^{\prime}{ }_{j}(t)}{n}, n=\left\{\begin{array}{l}
1, \text { year } \\
12, \text { month } \\
4, \text { season }
\end{array}\right. \\
I_{j}(1)=100
\end{gathered}
$$

\subsection{Cycle Measurement by window spectrum estimation}

The method of spectral analysis is relatively mature and has been introduced in many literature ${ }^{[10-12]}$. The deterministic periodic function, expanded by Fourier series under certain conditions, can be expressed as the sum of sine and cosine functions of different frequencies. If a smooth time series, $\left\{X_{t}\right\}$ is a periodic function with a period of $\mathrm{T}$, i.e.

$$
\begin{gathered}
X_{t}=A_{0}+\sum_{k=1}^{N}\left(a_{k} \cos 2 \pi f_{k} t+b_{k} \sin 2 \pi f_{k} t\right) \\
\text { Where } \\
f_{k}=k / T \quad \mathrm{k}=1,2, \ldots
\end{gathered}
$$

Function $f(\mathrm{~T})$ and function $\left\{X_{t}\right\}$ described time series from two different angles of frequency domain and time domain. Both of them express the same cycle fluctuations.

It is proved that the standardized spectral density $f(\tau)$ of $\left\{X_{t}\right\}$, is the Fourier transformation of its selfcorrelation function, if $\left\{X_{t}\right\}$ is a stationary sequence. $\left\{\gamma_{k}\right\}$ is the inverse Fourier transformation of $f(\tau)$.

It is proven that the $f(\tau)$ can also be written:

$$
f(\tau)=\frac{1}{2 \pi}\left[\gamma_{0}+2 \sum_{k=1}^{\infty} \gamma_{k} \cos (\mathrm{k} \tau)\right]
$$

The period-gram is used as an estimate of spectral density. In this paper, the period of economic cycle fluctuation is measured by Tukey-Hanning window spectrum estimation method. The truncated parameter $M$ takes the cycle length parameter L.

$$
\begin{aligned}
& \hat{h}\left(f_{j}\right)=\sum_{k=-M_{M}}^{M} w(k) \hat{R}(k) \cos 2 \pi f_{j} k \\
& =R(0)+2 \sum_{k=1}^{M} w(k) \hat{R}(k) \cos 2 \pi f_{j} k
\end{aligned}
$$

Where

$$
\begin{aligned}
& 0 \leq f_{j} \leq \frac{1}{2} \\
& \hat{p}\left(f_{j}\right)=\frac{\hat{h}\left(f_{j}\right)}{R(0)}=1+2 \sum_{k=1}^{M} w(k) \hat{r}(k) \cos 2 \pi f_{j} k
\end{aligned}
$$

Where

$$
w(k)=\left\{\begin{array}{c}
\frac{1}{2}\left[1+\cos \frac{\pi k}{M}\right] \\
0, \quad|k|>\mathrm{M}
\end{array},|k| \leq M\right.
$$

\section{AIR CARGO PROSPERITY}

\subsection{Data}

The data used in this paper are the historical data of the annual air cargo related indicators issued by the Civil Aviation Administration of China (CAAC) from 1995 to 2019. The reason for choosing 1995 is that CAAC has successively established six regional administrations and eight major airlines, and approved the establishment of 16 local airlines sicn1994. This paper also compares the cycle with rail freight in China, as well as US air cargo transport and global trade. The data of these indicators are from the National Bureau of Statistics of China, and the World Bank respectively. 


\subsection{Establishment of prosperity indicator group}

The benchmark indicator as the core representative of the industry should first be determined. Generally the total output of the industry will be chosen for the benchmark indicator. In this research the freight tonmiles (FTK) is selected as the benchmark indicator. The trend of the industry is finally reflected in its prosperity.

The indicators of the prosperity index system are selected from trade, investment, transport volume, human resources, aviation oil prices and other indicators that affect the development of air cargo. Due to the current air cargo statistics is relatively weak, some indicators have not been able to distinguish between freight, such as employees.

Trade, macroeconomic growth and express delivery are the most important factors affecting air cargo demand. Employees reflect the prosperity of the industry from the perspective of labor input. The total profit is the result of the joint action of market demand and enterprise cost. Product price is the result of the interaction between industry product supply and demand. When prices rise, so does the prosperity of the industry.

In this paper, the indicators are screened by the method of time difference correlation, and the composite index (CI) is calculated by the method of NBER. When calculating the $\mathrm{CI}$ this paper adopts the growth rate cycle analysis method like most scholars in the economic cycle analysis.

Taking the growth rate of FTK as the benchmark indicator, the time difference correlation coefficient of each index is calculated.

According to the correlation coefficient, the indicator system of air cargo prosperity composite index is as follows.

Table 1. Air cargo Prosperity Index Group

\begin{tabular}{|c|c|c|c|}
\hline \multirow{5}{*}{$\begin{array}{l}\text { Coinciding } \\
\text { indicators }\end{array}$} & $\begin{array}{c}\text { growth rate } \\
\text { of FTK }\end{array}$ & \multirow{5}{*}{$\begin{array}{l}\text { Leading } \\
\text { indicators }\end{array}$} & $\begin{array}{l}\text { growth rate of } \\
\text { cargo } \\
\text { transportation } \\
\text { revenue }\end{array}$ \\
\hline & $\begin{array}{l}\text { growth rate } \\
\text { of air cargo } \\
\text { carried }\end{array}$ & & $\begin{array}{c}\text { growth rate of } \\
\text { express } \\
\text { delivery } \\
\text { volume }\end{array}$ \\
\hline & $\begin{array}{c}\text { growth rate } \\
\text { of average } \\
\text { distance of } \\
\text { air cargo } \\
\text { carried } \\
\end{array}$ & & $\begin{array}{l}\text { real growth } \\
\text { rate of fixed } \\
\text { assets } \\
\text { investment in } \\
\text { civil aviation }\end{array}$ \\
\hline & $\begin{array}{l}\text { real growth } \\
\text { rate of trade }\end{array}$ & & $\begin{array}{c}\text { international } \\
\text { WTI crude oil } \\
\text { price }\end{array}$ \\
\hline & $\begin{array}{l}\text { growth rate } \\
\text { of cargo } \\
\text { throughput }\end{array}$ & & $\begin{array}{l}\text { growth rate of } \\
\text { air transport } \\
\text { employees }\end{array}$ \\
\hline
\end{tabular}

\subsection{Air cargo Prosperity Index}

\subsubsection{Air cargo Prosperity Diffusion Index (DI)}

The time when the DI crosses the $50 \%$ line is the focus of business cycle analysis. The year before the DI crosses the $50 \%$ line is the base date of the air cargo prosperity bottom, and the year before the top-down crossing of the $50 \%$ line is the base date of the air cargo prosperity peak. It is divided into expansion and contraction according to the base date.

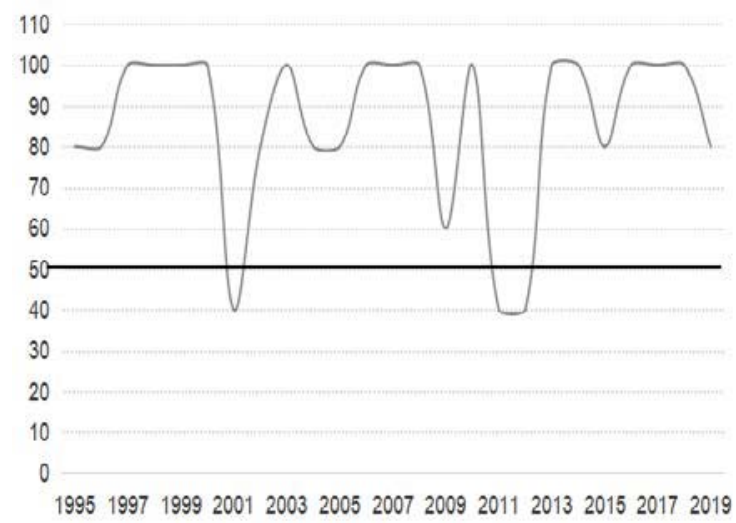

Fig. 1. Air cargo DI

Table 2. Base date table obtained by DI

\begin{tabular}{|c|c|}
\hline Peak & Bottom \\
\hline & 1995 \\
\hline 1998 & 2001 \\
\hline 2002 & 2009 \\
\hline 2008 & 2010 \\
\hline 2012 & \\
\hline
\end{tabular}

It can be seen that air cargo was in a depressed space in 1998 and 2002 due to the global financial and economic crisis. Then it reached the peak of the air cargo again in 2010. The industry has been recovered after the global economic crisis in 2012. According to the DI, it can be seen that the periodic fluctuation of air cargo from 1995 to 2019 was small, and the period of expansion or contraction is generally 2-3 years.

\subsubsection{Air cargo Prosperity Composite Index (Cl)}

The CI is calculated by the NBER method, and 2002 is selected as the base year considering that it is relatively stable. The results of the $\mathrm{CI}$ are as follows: 


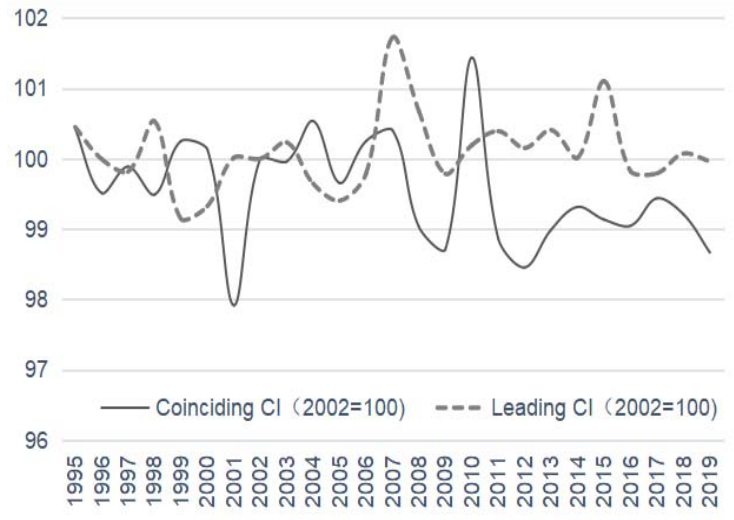

Fig. 2 the coinciding and leading CI of China air cargo

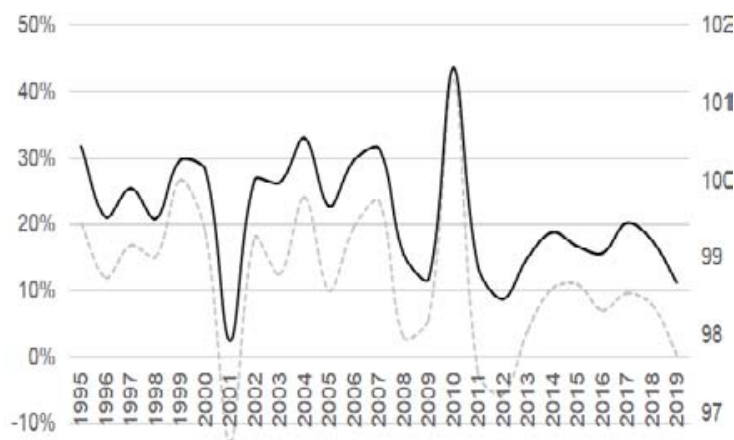

$-20 \%-\ldots .$. FTK growth rate $\quad$ Coinciding $\mathrm{Cl}(2002=100) \quad 96$

Fig. 3 trend of coinciding CI and the FTK growth rate

According to the time difference correlation and combined with figure 2 , it is indicated that the length of the leading CI ahead of the coinciding CI is 2-3 years. According to the trend of the coinciding CI, China's air cargo has increased significantly with the growth of global trade, but it is also very vulnerable to external factors. For example, the $9 / 11$ incident in 2001, the financial crisis in 2008, as well as the sub-prime crisis and the global trade friction in 2019 all affected the global air cargo industry, which caused a short but very obvious impact on the low point of the air cargo prosperity index in the depressed space, and raise again in 2015. In addition, taking 2002 as the dividing point, the coefficient of variation of the CI from 1995 to 2002 is higher than that from 2003 to 2019 , and the average value of the former is also higher than that of the latter, but the difference is small (99.7 and 99.5), indicating that the prosperity of air cargo is not high for a long time, and its volatility is small. From the standard deviation and variation of the CI, it can be seen that the fluctuation from 1995 to 2002 is large, and the stability is relatively poor. This is related to the long-term development of civil aviation, more focus on the passengers than the cargo, as well as the complex and changeable global trade situation.

Compared with the trend of the benchmark indicators, it can be seen that although the general status of air cargo fluctuates a lot, there is basically no continuous decline or entering the decline channel, which can be regarded as a steady adjustment. Even with the slowdown in macroeconomic growth since 2010, the air cargo prosperity index is still relatively stable.

GDP and industrial value added are the basic indicators of coinciding indicators in the internationally recognized economic trend analysis, but from the perspective of industry prosperity, GDP growth rate and trade growth rate are selected as the verification indicators of air cargo CI. It can be seen from figure 4 that the changing trend of the air cargo $\mathrm{CI}$ is consistent with that of GDP and trade, which proves the rationality and validity of the prosperity index of air cargo.

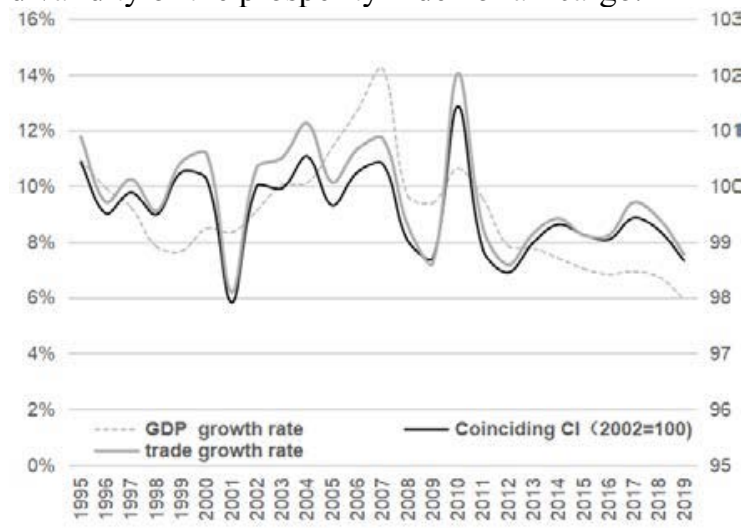

Fig. 4 comparison of real growth rate of GDP, trade growth rate and $\mathrm{CI}$ of air cargo

\subsection{Measurement of Air cargo cycle based on Spectral Analysis}

The cycle of air cargo of China and the United States is measured by spectral analysis. The cycle of China's air cargo is measured based on the air cargo CI calculated above, while the measurement indicators of US air cargo and Chinese railway freight are the growth rate of FTK of air cargo and FTK of railway.

The results of ADF test of each indicator show that each sequence is stationary, and the window spectrum analysis method can be instructed. The results show that the main cycle of air cargo since 1995 is 3.6 years, which is basically consistent with the air cargo cycle of the United States and the fluctuation cycle of global trade. Compared with air cargo, the main cycle of railway freight is 12.5 years, and the fluctuation is relatively stable, which also reflects that railway freight occupies a larger share of the domestic freight market, while air freight is more affected by international trade. In a longer time period (1975-2019), the air cargo cycle is still in the range of 3-4 years, which also shows that the short-term volatility of air cargo lasts for a longer period of time.

Under the influence of the epidemic, air cargo demand decreased in 2020, but higher than that in 2001 . The first few months of 2021 have returned to even exceeded the pre-epidemic levels. The World Trade Organization forecast that global trade in goods will grow by $8.0 \%$ and $4.0 \%$ in 2021 and 2022 respectively. Considering the leading index is 2-3 years ahead of the coinciding index, and the leading index starts an upward trend in 2018. China's air cargo is expected to reach a small peak in 2021-2022 after hitting the bottom in 2020. 


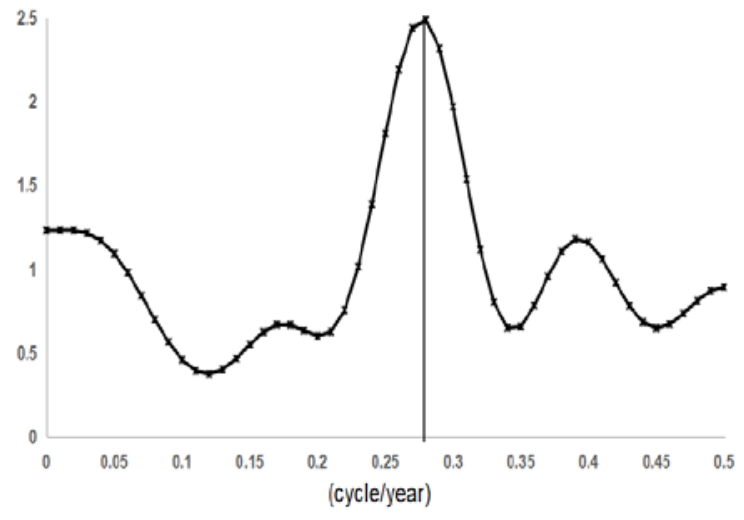

Fig. 5 Air cargo cycle spectrum of China

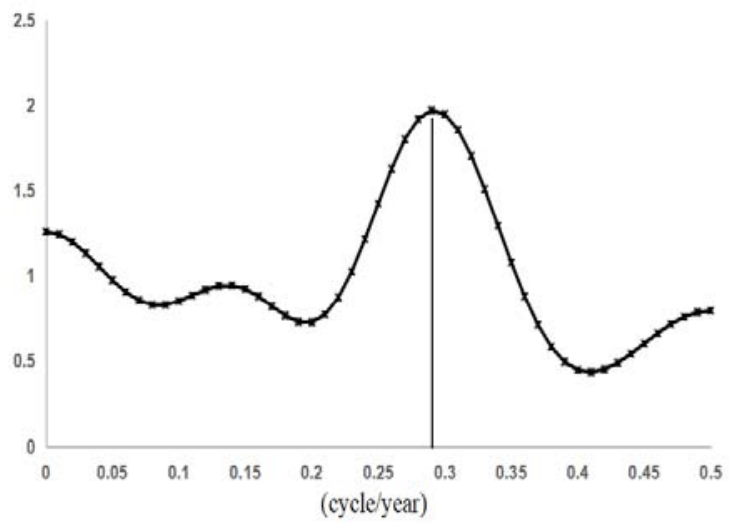

Fig. 6 Air cargo cycle spectrum of United States

\section{Conclusions}

Through the above analysis, the following conclusions can be drawn. The economy, especially the trade growth rate will have a certain exogenous impact on the air cargo. There are periodic fluctuations in the air cargo demand trend. According to the China air cargo CI in 1995-2019, the length of the main cycle is 3.6years, which is consistent with the fluctuation cycle of global trade. Combined with the trend of leading index, the growth of China's air cargo faces a wavelet peak during the 14th five-year Plan period. It is feasible to measure the prosperity index and the cycle based on the annual data.

\section{References}

1. Burns A.F. and W.C. Mitchell, Measuring Business Cycles, NBER, 1946

2. Geoffrey H. Moore. Statistical Indicators of Cyclical Revivals and Recessions. NBER, 1950

3. Julius Shiskin, Geoffrey H. Moore, Composite Indexes of Leading, Coinciding, and Lagging Indicators, NBER.1968

4. Wenquan Dong, Tiemei Gao, Shizhang Jiang, Lei Chen. Analysis and Forecasting Methods of Economic Cycles. Jilin University Press, 1998
5. Chenyu, Research on Civil Aviation Economic Prosperity Monitoring and early warning system, Beijing Jiaotong University, 2009

6. Guan Jing, Li Xueyan. Analysis of China Civil Aviation Transportation Industry based on Prosperity Index, Journal of Civil Aviation University of China, (3) 2012

7. Zhao ChenShihui, Zhu JC. Construction and application of railway freight market prosperity index. China Railway, (2) 2016

8. C. Lu, etal., Research and practice of China Air cargo Prosperity Index. Chinese Market, 2018

9. J. Ge, Y. He, F. Zhan, "Measuring the Cycle of Air Cargo Transport in China based on Spectrum Analysis," 2020 IEEE 2nd International Conference on Civil Aviation Safety and Information Technology

10. Granger, C. W. J. and Hatanaka, M. Spectral Analysis of Economic Time Series, 1964

11. Ma Yejiang, Hu Siji, Wu Xu. The Spectral Analysis of Transportation Economy Cycle Fluctuation. Journal of Beijing Jiaotong University: Social Science Edition, 2008

12. Wang P, Jones T. A Spectral Analysis of Business Cycle Patterns in UK Sectoral Output[J]. Working Papers, 2008 